\title{
THE TRANSVERSE DIAMETER OF THE HEART IN OLDER PEOPLE
}

\author{
BY \\ NAIRN R. COWAN \\ From the Consultative Health Centre for Older People, Rutherglen, Lanarkshire
}

Received August 24, 1959

In this paper measurements of the transverse diameter of the heart are presented in persons aged 60 to 79 years, using X-ray films of the chest, together with data on their body weight, height, chest diameter, and arterial blood pressure. The object is to determine the nature and intensity of the relationships of the heart diameter and these other factors, and therefrom to assess the efficiency with which the heart diameter can be predicted from a knowledge of such variables in a healthy but elderly group of the population. The differences in these respects with change of age will also be indicated by contrasting the findings for adjacent decennial periods 60 to 69 and 70 to 79 years.

Many authors have regarded the heart diameter as a useful criterion of the heart size itself (Bedford and Treadgold, 1931; Bainton, 1932; Bakwin and Bakwin, 1935; Comeaú and White, 1942) but, as far as I am able to ascertain, information relates to those of young and adult life and only inadequately to old age. A statistical study similar in character to the present was carried out by Hodges and Eyster (1926) using orthodiagrams derived from 80 men between the ages of 15 and 45 years.

\section{METHODS}

The data are derived from the records of 111 men and 160 women, aged 60 to 69 years, and 123 men and 129 women, aged 70 to 79 years, who attended the Rutherglen Consultative Health Centre for older people (Anderson and Cowan, 1955). All were considered to be in good health after a complete clinical examination which included ophthalmoscopic and rectal examinations. Excluded from the series were those who had a hæmoglobin under $11 \mathrm{~g}$. Sahli, an apical systolic murmur greater than Grade 2 as described by Levine and Harvey (1949), or an asymmetrical chest. For the purpose of this statistical study the adipose who were otherwise in good health have been included. Subjects suffering from extreme degrees of adiposity usually excluded themselves because of co-existing disease or inability to measure the heart or chest diameters with accuracy.

The transverse diameters of the heart and chest were measured to the nearest millimetre from X-ray films taken in the postero-anterior position at a distance of two metres with an exposure of $1 / 25$ second at 300 milliampres as previously described (Cowan, 1959). Weight was measured to the nearest quarter pound $(120 \mathrm{~g}$.) and height to the nearest quarter of an inch $(0.6 \mathrm{~cm}$.). The men and women wore a minimum of clothing and no footwear. The weighing machine was of the steelyard platform type reading accurately to $3 \mathrm{oz}$. (90 g.), with a height measuring attachment.

Arterial blood pressure was estimated by the auscultatory method to the nearest even number, and a mercury manometer with standard cuff was used. Systolic blood pressure was recorded at the point at which sounds were first heard, and diastolic blood pressure at the point of sudden muffling which occurs prior to the disappearance of the sounds. The blood pressure of each subject was taken on several occasions and the last one noted in every case was used in this paper. 


\section{RESULTS}

Table I shows for each sex the means with their standard errors, the standard deviations, and the coefficients of variation of the several variables for two decennial age groups. The average heart diameters are alike for the sexes in the age group 60 to 69 years, but in the following decade the heart diameter of the men is on average $0.4 \mathrm{~cm}$. greater than that of the women. The average values of the heart diameters of $12.6 \mathrm{~cm}$. and $13.0 \mathrm{~cm}$. in the men are greater than the $12.2 \mathrm{~cm}$. recorded by Kerley (1950) for adult men, and the heart diameter means of the women are $2 \mathrm{~cm}$. greater than the $10.7 \mathrm{~cm}$. observed for adult women by Bainton (1932) from orthodiagrammatic studies. The diminution in the average body weight with age is rather more pronounced in women. Chest diameter decreases in both sexes with age, and the standard errors of these means suggest that the downward trend is significant in women but not in men. The average systolic and diastolic blood pressures of the women are greater than the corresponding values for the men in both age groups, and while systolic blood pressure increases with age in both sexes, diastolic pressure shows no such change with age. The men are taller on average than the women and for each sex the differences in the two age groups are negligible.

The absolute variability of heart diameter (measured by the standard deviation) is equal in the sexes; shows no change with age; is less than that of other attributes such as body weight and blood pressure, and is comparable to the value of 1.09 noted by Hodges and Eyster (1926). The relative variability of heart diameter (measured by the coefficient of variation) is alike for the sexes; shows no change with age; is less than that for weight and blood pressure, but greater than that for chest diameter and height.

The approximate relative variability of 8.9 for the heart diameter, which is analogous to the $7 \cdot 7$ observed for the cardiothoracic ratio (heart-lung coefficient; Cowan, 1959), is moderate. Body weight and arterial blood pressure are more variable attributes, and the use of heart diameter as a clinical index cannot, therefore, be criticized on the grounds of its excessive variability in different subjects.

TABLE I

Means, Standard Deviations, and Coefficients of Variation of the several Variables by Sex and ten-year AGE GROUPS

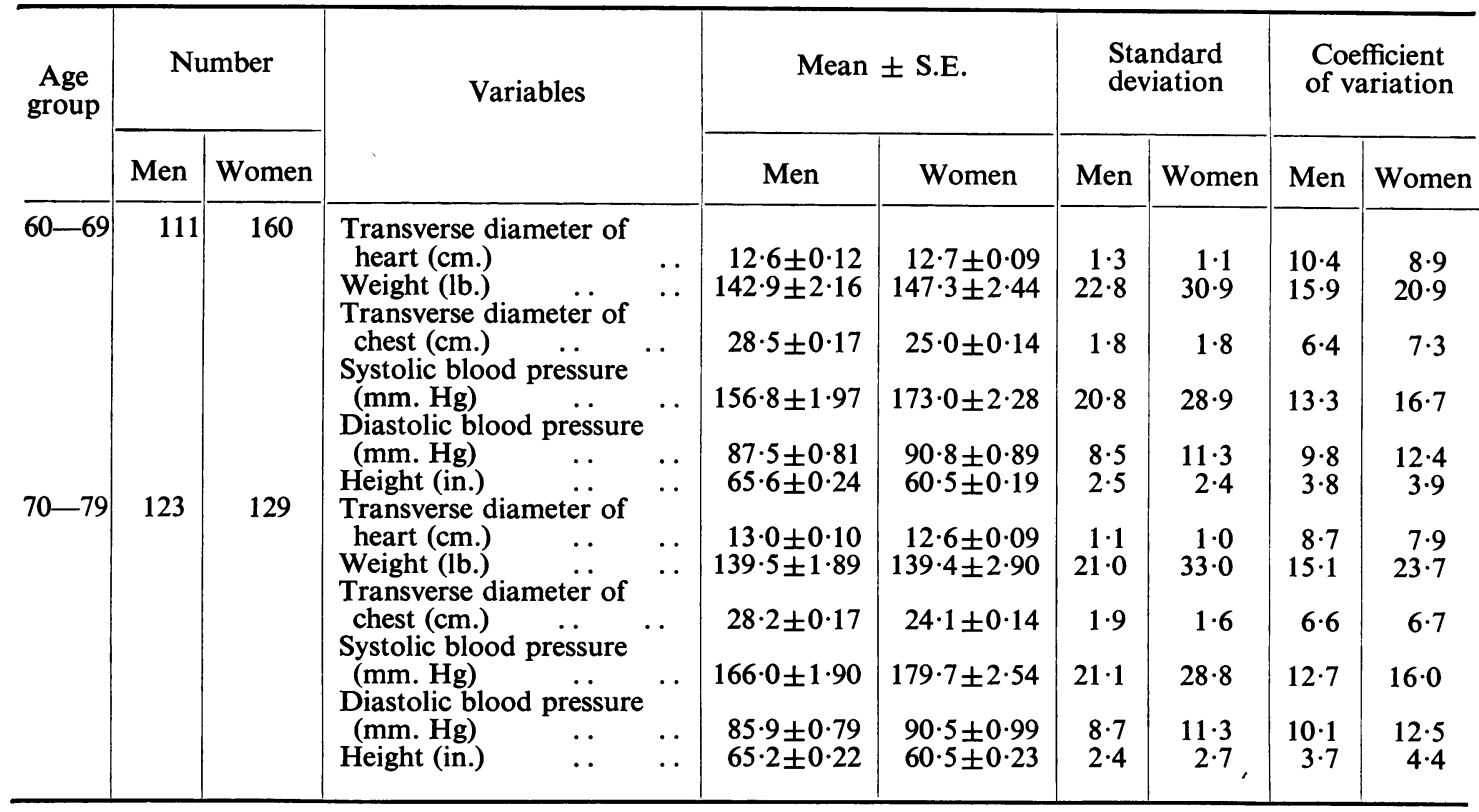


The coefficients of correlation* for the four age-sex groups for each pair of variables were calculated. The closest relationships between heart diameter and other variables are those involving weight and chest diameter. Arterial blood pressure though significantly correlated with heart diameter is of less importance, while between height and heart diameter the association, though positive in sign, is not significant statistically. These coefficients of correlation do not take into account the interrelationships that exist in varying degree between the variables themselves, and in consequence do not measure the strength of association between the heart diameter and each of the other variables when the influence of the remaining independent variables has been eliminated. This is measured by coefficients of partial correlation between heart diameter and each variable separately, one or more of the others being held constant. The third order coefficients of correlation* indicate that when the three residual variables are held constant, (1) the significance of the correlations between the heart diameter and each variable is diminished, (2) weight and chest diameter remain the most important correlatives of heart diameter, and (3) the strength of association in each sex is less in the later than in the earlier decade, except in respect of the correlation between heart diameter and systolic or diastolic blood pressure in women, and between heart diameter and systolic blood pressure in men. Furthermore, heart diameter and height, which considered by themselves show a positive association, are when the remaining variables are held constant, if anything, negatively correlated but to a degree that is of doubtful significance.

In view of the decided association between these other attributes and heart diameter the high initial variability of this diameter (Table I) can clearly be reduced when a knowledge of these other variables is available. The extent of this reduction when such knowledge is utilized is apparent on comparison of the partial standard deviations (Table II) with the initial crude values (Table I). They show that for constant weight, chest diameter, systolic blood pressure, and height, the absolute

TABLE II

Partial Standard Deviations for the Transverse Diameter of the Heart by Sex and ten-year Age Groups WITH REFERENCE TO ALL OTHER VARIABLES

\begin{tabular}{|c|c|c|c|c|}
\hline \multirow{3}{*}{ Subscript $\dagger$} & \multicolumn{4}{|c|}{ Partial standard deviations } \\
\hline & \multicolumn{2}{|c|}{$60-69$ years } & \multicolumn{2}{|c|}{$70-79$ years } \\
\hline & Men & Women & Men & Women \\
\hline $\begin{array}{l}1 \text { with } 2346 \\
1 \text { with } 2356\end{array}$ & $\begin{array}{l}0.85 \\
0.82\end{array}$ & $\begin{array}{l}0.69 \\
0.72\end{array}$ & $\begin{array}{l}0 \cdot 88 \\
0 \cdot 88\end{array}$ & $\begin{array}{l}0.75 \\
0.77\end{array}$ \\
\hline
\end{tabular}

$\dagger$ The subscripts are: 1. Transverse diameter of heart. 2. Weight

3. Transverse diameter of chest.
4. Systolic blood pressure.

5. Diastolic blood pressure.

6. Height.

Diastolic blood pressure is an alternative for systolic blood pressure.

variability of the heart diameter is reduced by 35 per cent and 37 per cent for men and women respectively in the earlier, and by 20 per cent and 25 per cent for men and women respectively in the later age group. There is no material difference in this respect if diastolic is substituted for systolic blood pressure in the assessment.

A further important point to determine is the relative strength of the association between the heart diameter and the various combinations of the independent variables. This is indicated by comparison of the coefficients of multiple correlation*. The salient feature is that for each sex and age group the coefficients of multiple correlation involving body weight and chest diameter are little

* Tables of relevant data may be obtained from the author. 
less than the corresponding coefficients involving all four independent variables. Furthermore, virtually all the coefficients of multiple correlation show less strength of association in the older than in the younger age group.

Equations predicting heart diameter in terms of body weight and chest diameter are therefore quite as efficient as those using all four variables*, and are as follows.

$\begin{array}{lll}\text { 60-69 years. } & \text { Men. } & X_{1}=0.02571 \mathrm{x}_{2}+0.2433 \mathrm{x}_{3}+1.9944 \\ & \text { Women. } & \mathrm{X}_{1}=0.01890 \mathrm{x}_{2}+0.2245 \mathrm{x}_{3}+4.2778 \\ 70-79 \text { years. } & \text { Men. } & \mathrm{X}_{1}=0.01656 \mathrm{x}_{2}+0.2142 \mathrm{x}_{3}+4.6581 \\ & \text { Women. } & \mathrm{X}_{1}=0.01232 \mathrm{x}_{2}+0.1951 \mathrm{x}_{3}+6.1876\end{array}$

where $\mathrm{X}_{1}=$ transverse diameter of heart (cm.), $\mathrm{x}_{2}=$ weight (lb.), and $\mathrm{x}_{3}=$ transverse diameter of chest (cm.). The predictive efficiency of these equations is approximately 34 per cent at $60-69$ years and 20 per cent in the later age group.

The only other attempt of which I am aware to predict the heart diameter in terms of other variables is that of Hodges and Eyster (1926), who studied a group of young adult men aged approximately 15 to 45 years and related heart diameter to age, height, and weight. The predictive efficiency of their equation was of the order of 19 per cent. In the old people of this series the value of the equations for prediction using these variables is not less satisfactory, and those predicting heart diameter from body weight and chest diameter are appreciably better for age group 60 to 69 years and equally so for ages 70 to 79 years. In addition, this paper, unlike that of Hodges and Eyster (1926) which is based on orthodiagrammatic measurements, presents equations that refer to X-ray films, and in the evaluation of X-ray films consequently require no correction.

\section{SUMMARY}

The transverse diameter of the heart in 523 healthy old people, aged 60 to 79 years, is examined and related to the other attributes body weight, transverse diameter of chest, arterial blood pressure, and height.

In this series the average heart diameter differs little in older men and women, and its relative variability of 8.9 is moderate. Body weight and arterial blood pressure are more variable attributes.

The transverse diameter of the heart is significantly related to each of the other variables mentioned, most appreciably with body weight and with the transverse diameter of the chest. When the other variables are held constant the predominating influence of body weight and the transverse diameter of the chest emerges.

Multiple regression equations are presented predicting the transverse diameter of the heart in terms of the two most important variables. These indicate that in any accurate decision on cardiac enlargement it is essential to take into account body weight and chest diameter.

I wish to thank Dr. P. L. McKinlay of the Department of Health for Scotland for helpful advice. Tables of the relevant data marked with an asterisk may be obtained from the author.

\section{REFERENCES}

Anderson, W. F., and Cowan, N. R. (1955). Lancet, 2, 239.

Bainton, J. H. (1932). Amer. Heart J., 7, 331.

Bakwin, H., and Bakwin, R. M. (1935). Amer. J. Dis. Child., 49, 861.

Bedford, D. E., and Treadgold, H. A. (1931). Lancet, 2, 836.

Comeau, W. J., and White, P. D. (1942). Amer. J. Roentgenol., 47, 665.

Cowan, N. R. (1959). Brit. Heart J., 21, 228.

Hodges, F. J., and Eyster, J. A. E. (1926). Arch. intern. Med., 37, 707.

Kerley, P. (1950). A Text-book of X-ray Diagnosis, p. 19. Lewis, London.

Levine, S. A., and Harvey, W. P. (1949). Clinical Auscultation of the Heart, p. 145. Saunders, Philadelphia. 